\title{
Deep Learning Algorithms and Multicriteria Decision-Making Used in Big Data: A Systematic Literature Review
}

\author{
Mei Yang $\left(\mathbb{D},{ }^{1}\right.$ Shah Nazir $\mathbb{D},{ }^{2}$ Qingshan $\mathrm{Xu}^{3}$ and Shaukat $\mathrm{Ali}^{4}$ \\ ${ }^{1}$ School of Politics and Public Administration, Collaborative Innovation Center of National Security Research, \\ Xinjiang University, Urumuqi 830046, China \\ ${ }^{2}$ Department of Computer Science, University of Swabi, Khyber Pakhtunkhwa, Pakistan \\ ${ }^{3}$ School of Management and Economics, Beijing Institute of Technology, Bejing 100081, China \\ ${ }^{4}$ Department of Computer Science, Islamia College University, Peshawar, Pakistan \\ Correspondence should be addressed to Mei Yang; yangmei@xju.edu.cn
}

Received 28 June 2020; Accepted 20 July 2020; Published 17 August 2020

Guest Editor: M. Irfan Uddin

Copyright (C) 2020 Mei Yang et al. This is an open access article distributed under the Creative Commons Attribution License, which permits unrestricted use, distribution, and reproduction in any medium, provided the original work is properly cited.

\begin{abstract}
The data are ever increasing with the increase in population, communication of different devices in networks, Internet of Things, sensors, actuators, and so on. This increase goes into different shapes such as volume, velocity, variety, veracity, and value extracting meaningful information and insights, all are challenging tasks and burning issues. Decision-making based on multicriteria is one of the most critical issues solving ways to select the most suitable decision among a number of alternatives. Deep learning algorithms and multicriteria-based decision-making have effective applications in big data. Derivations are made based on the use of deep algorithms and multicriteria. Due to its effectiveness and potentiality, it is exploited in several domains such as computer science and information technology, agriculture, and business sector. The aim of the proposed study is to present a systematic literature study in order to show the applications of deep learning algorithms and multicriteria decision approaches for the problems of big data. The research finds novel means to make the decision support system for the problems of big data using multiple criteria in integration with machine learning and artificial intelligence approaches.
\end{abstract}

\section{Introduction}

With the increase in population, communication of different devices in networks, Internet of Things, sensors, actuators, and so on, the size of data is increasing. This increase goes into different shapes such as volume, velocity, variety, veracity, and value extracting meaningful information and insights which are challenging tasks and burning issues. According to IDC [1], in late 2011, about $1.8 \mathrm{ZB}$ of data was created. Globally, per year about $1.2 \mathrm{ZB}\left(10^{21}\right)$ is generated by different sources as electronic data [2]. By 2020, data are expected to $40 \mathrm{ZB}$ [3]. Tools and techniques should be available to handle big data in an easy and effective way. The tools should have the capability to process the data, apply different filtering process to extract meaningful insights, cooperate, and communicate with other tools during data exchange.
Decision-making on big data based on multicriteria is one of the challenging issues for researchers and practitioners. To make decision based on appropriate numbers of choices, effectiveness, and potentiality, researchers are finding novel means to make the decision support system for the problems of various application domains of big data by using multiple criteria in integration with machine learning and artificial intelligence. Several decision support systems are available which have the potential to support decision-making activities [4-7]. Decision-making plays an important role in the success of a business or an organization. Based on multiple criteria, the decision-making is difficult as there are several available criteria for the decision to take action.

In the recent approaches for solving problems of big data, the decision support systems are facilitated with the integration of deep learning algorithms to provide a more intelligent decision support system [8-10]. The decision support system has several applications in diverse areas such 


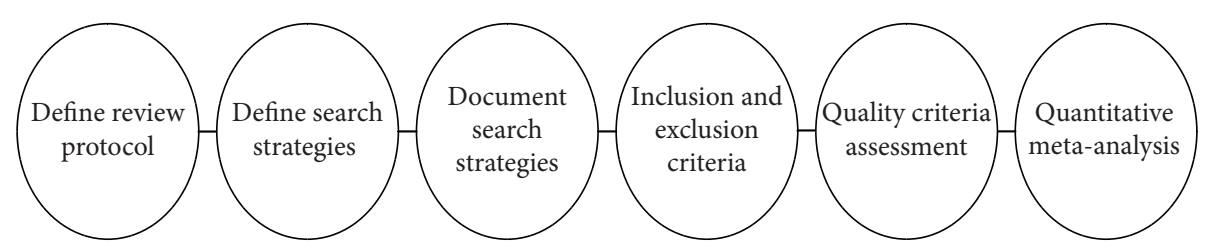

FIGURE 1: Generic process of SLR.

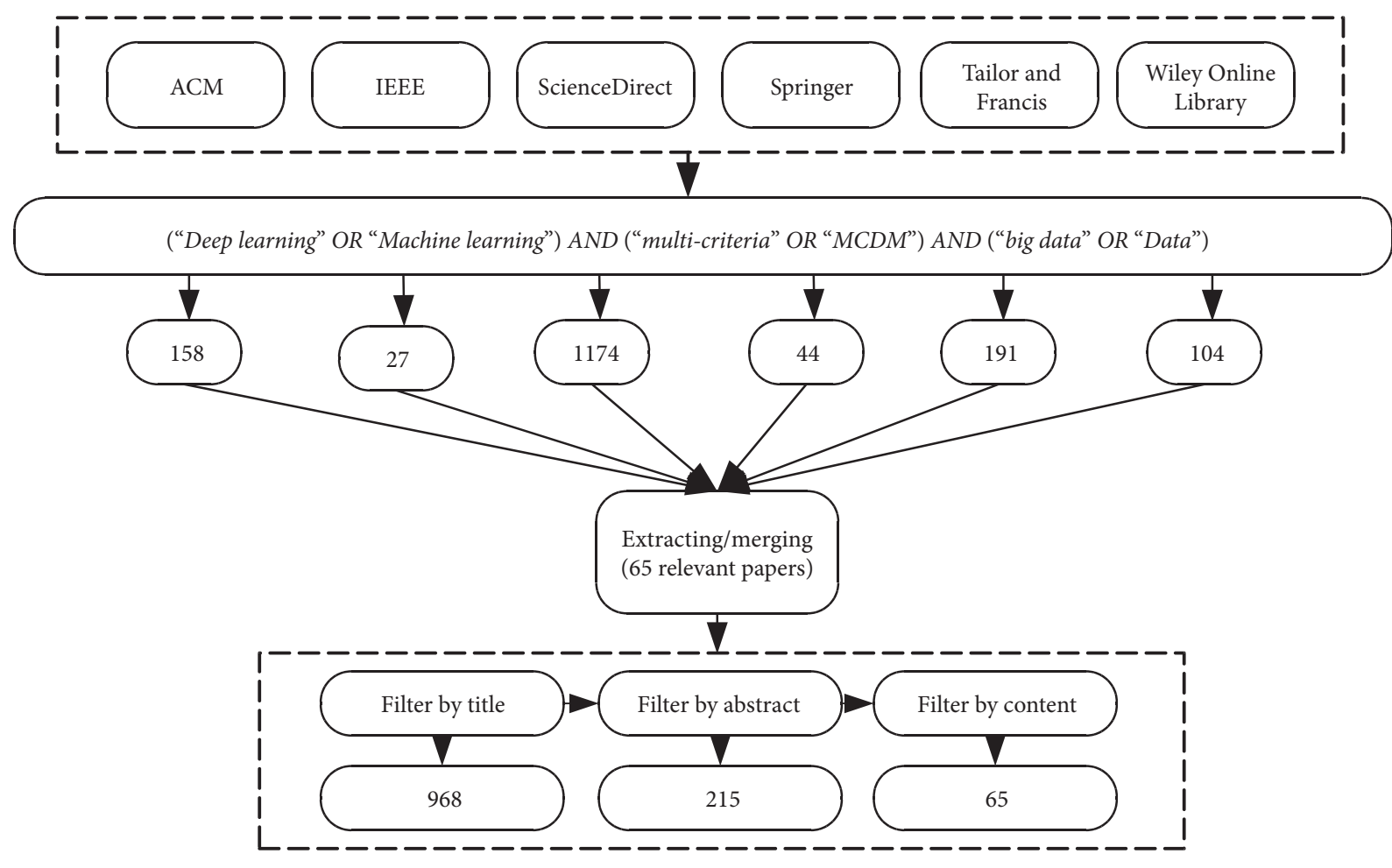

FIGURE 2: Search and filtering process of the proposed study.

TABLE 1: Summary statistics of query execution in the given libraries.

\begin{tabular}{|c|c|c|c|c|}
\hline Libraries & Keyword query & Total & Included & Span of time \\
\hline $\mathrm{ACM}$ & $\begin{array}{c}\text { ("Deep learning" OR "Machine learning") AND ("multi-criteria" OR "MCDM") AND } \\
\text { ("big data" OR "Data") }\end{array}$ & 158 & 8 & $2016-2020$ \\
\hline IEEE Xplore & $\begin{array}{c}\text { ("Deep learning" OR "Machine learning") AND (“multi-criteria" OR "MCDM") AND } \\
\text { ("big data" OR "Data") }\end{array}$ & 27 & 12 & $2016-2020$ \\
\hline ScienceDirect & $\begin{array}{c}\text { ("Deep learning" OR "Machine learning") AND ("multi-criteria" OR "MCDM") AND } \\
\text { ("big data" OR "Data”) }\end{array}$ & 1174 & 28 & $2016-2020$ \\
\hline Springer & $\begin{array}{c}\text { ("Deep learning" OR "Machine learning") AND ("multi-criteria" OR "MCDM") AND } \\
\text { ("big data" OR "Data") }\end{array}$ & 44 & 7 & 2016-2020 \\
\hline $\begin{array}{l}\text { Taylor and } \\
\text { Francis }\end{array}$ & $\begin{array}{c}\text { ("Deep learning" OR "Machine learning") AND ("multi-criteria" OR "MCDM") AND } \\
\text { ("big data" OR "Data") }\end{array}$ & 191 & 5 & $2016-2020$ \\
\hline Wiley Online & $\begin{array}{c}\text { ("Deep learning" OR "Machine learning") AND ("multi-criteria” OR "MCDM") AND } \\
\text { ("big data" OR "Data") }\end{array}$ & 104 & 5 & $2016-2020$ \\
\hline
\end{tabular}

as business [11], energy sector [12], and agriculture [13]. Various domains explain the theories and methods which come from simple to more advanced and intelligent models for decision making $[14,15]$.

Keeping in view the effectiveness and importance of adopting the decision support system (DSS) along with the use of deep learning algorithms, the proposed study presents a systematic literature review of the last five (05) years from 2016 to 2020 . The aim of the proposed study is to identify the trends, scope, and methods from the existing literature in order to present an improved decision support system with integration of deep learning solutions to tackle big data. Keywords were defined based on the research questions for conducting the survey, and the papers were included based on the criteria of 


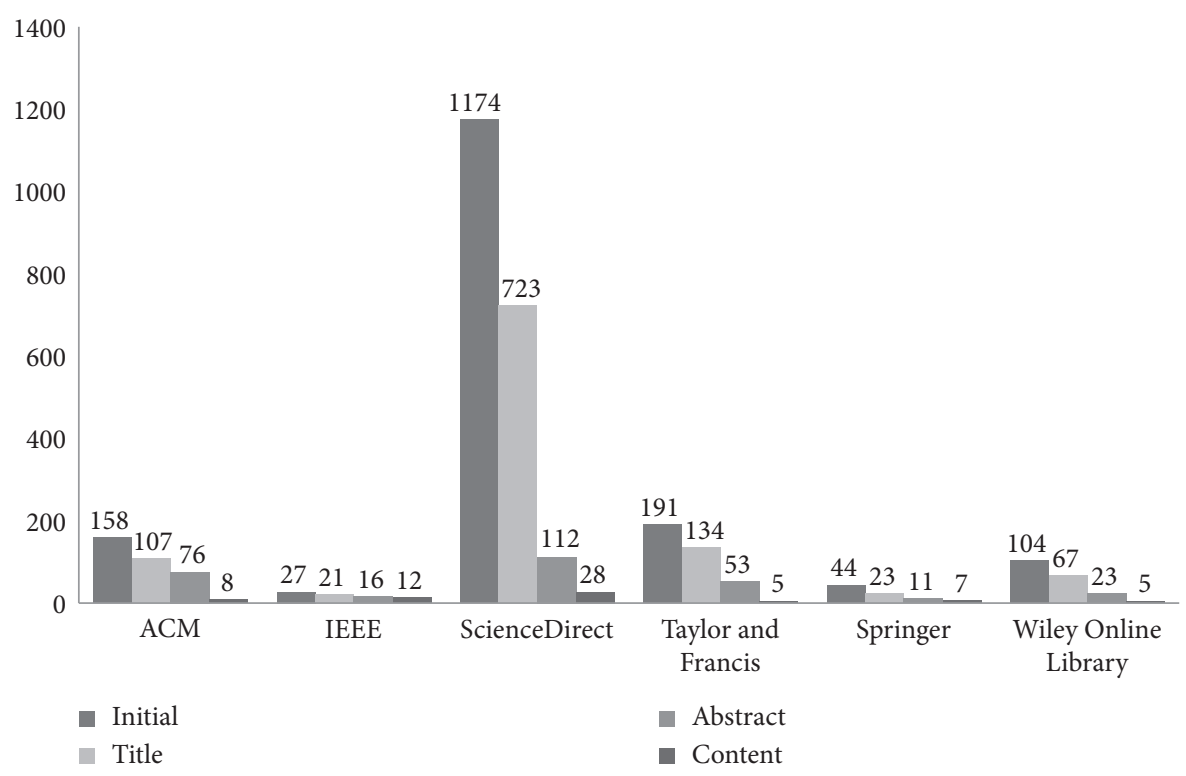

FIGURE 3: Search and filtering results.

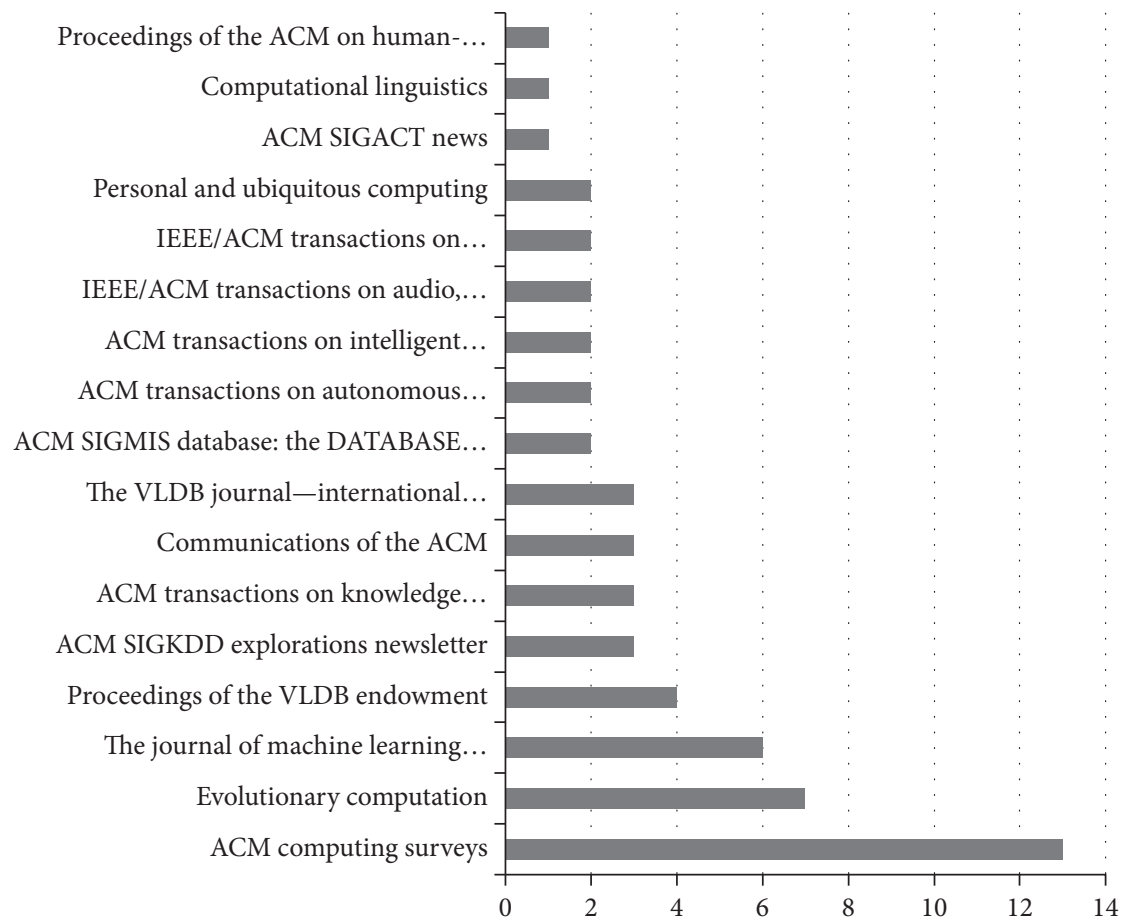

FIGURE 4: Initial results of the journal/magazine names along with the total number of publications.

quality assessment. The selected papers from the literature were further analysed to answer the research questions of the study.

Experimental results of the proposed study show that deep learning algorithms and decision support systems are exploited in a useful way. The research integrated power machine learning as well as artificial intelligence and multicriteria decision-making models to provide effective solutions to problems which are more complex.

The organization of the paper is as follows: next section represents the research method with the details of the protocol followed for conducting the proposed research. Section
3 represents the results and discussion section of the paper with the analysis of answering the research questions. The paper concludes in Section 4.

\section{Research Method}

Systematic literature review is a protocol of conducting literature review of a specific research and systematically collects the research papers based on the defined research questions and keywords, analyzing the selected studies in order to assess the applications and impact of the study. 


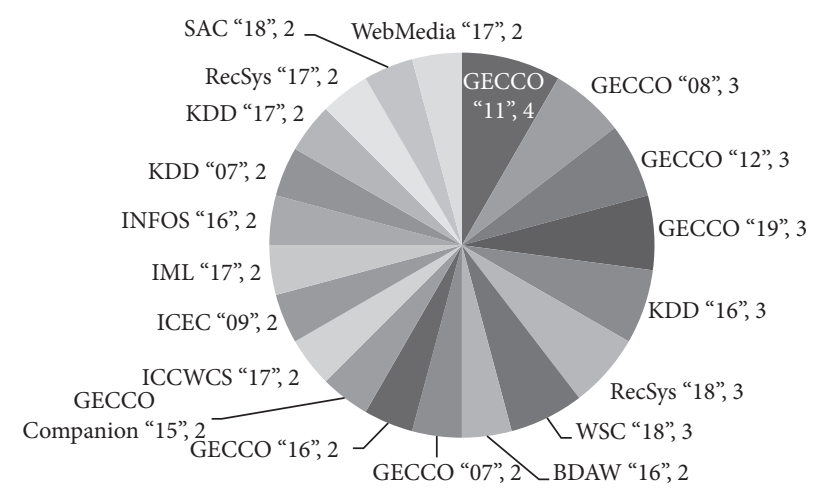

FIGURE 5: Proceeding names with the number of papers.

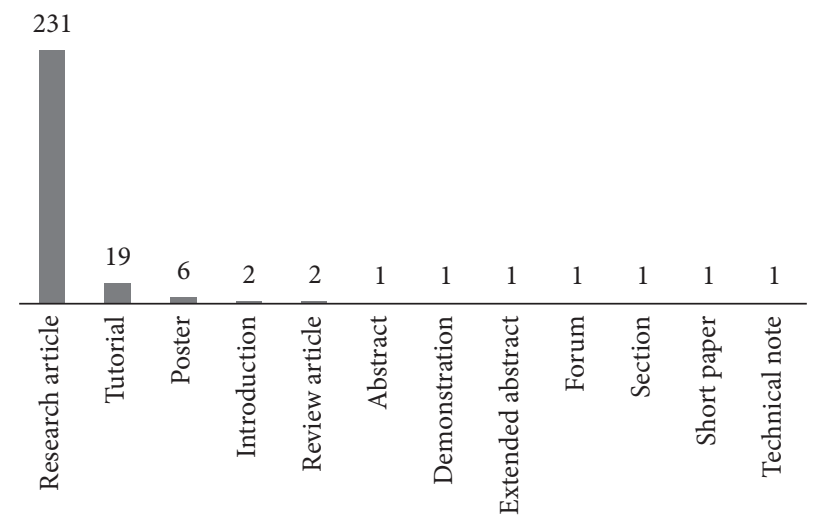

no. of paper

FIgURE 6: Content types with the number of papers.

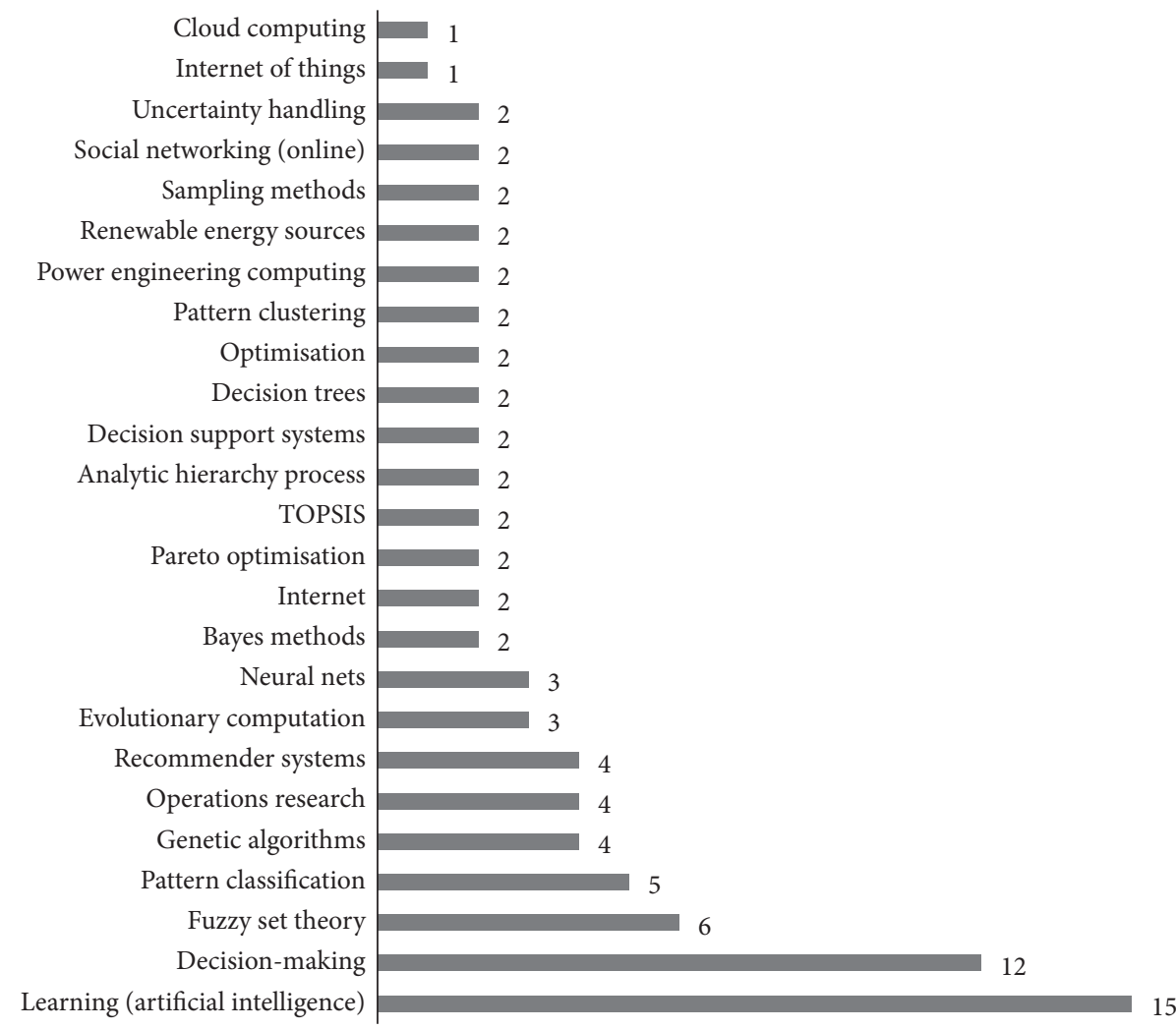

FIgURE 7: Publication topics with the number of papers. 


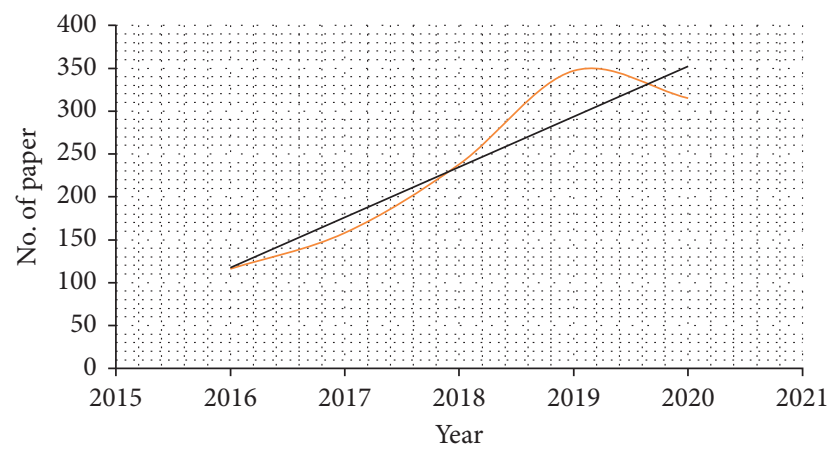

Figure 8: Number of publications in the given years.

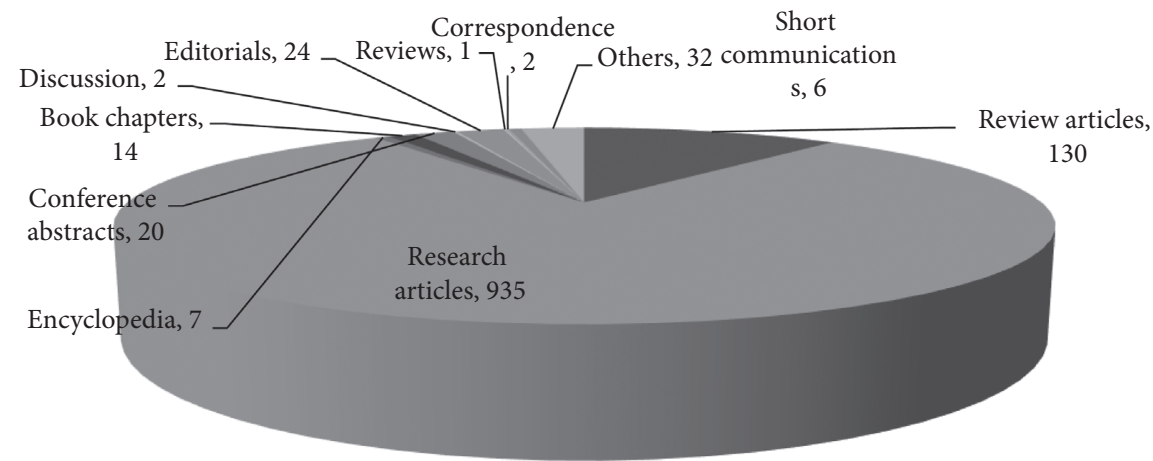

FIGURE 9: Article types with the number of papers.

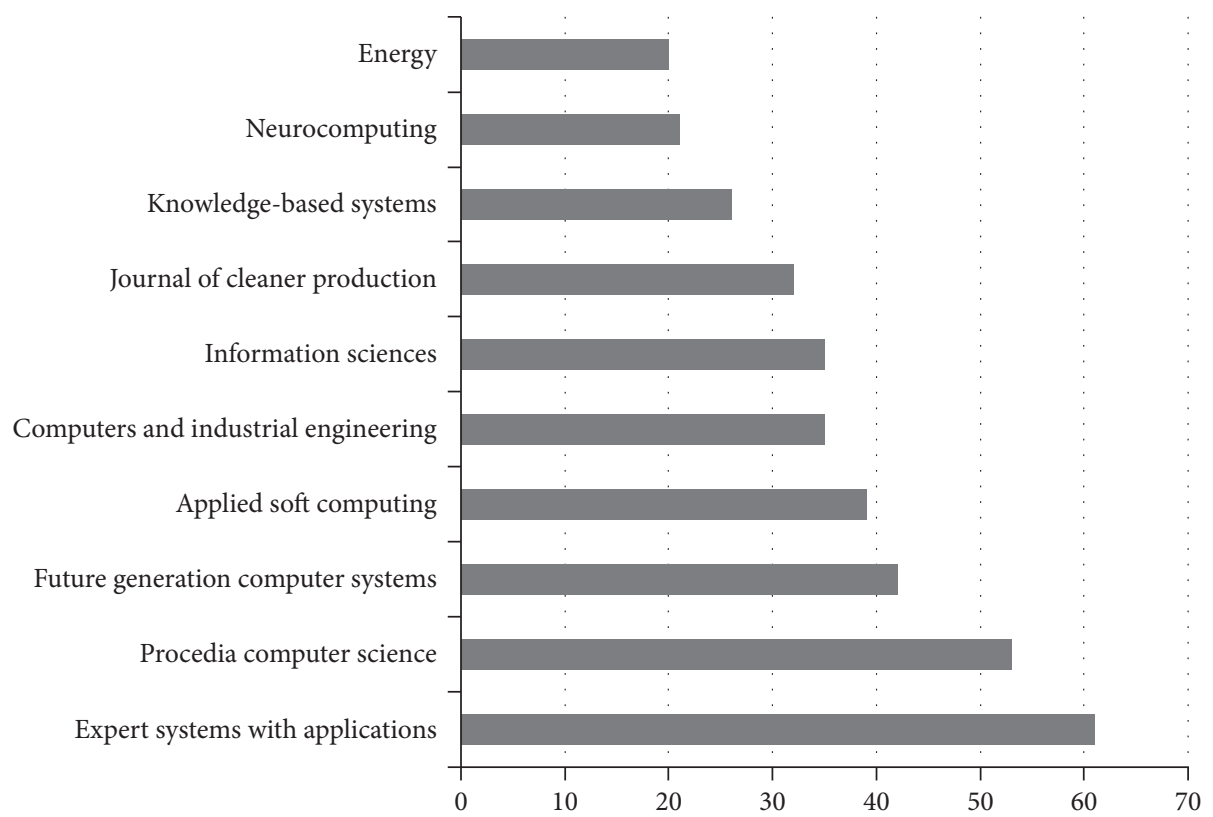

Figure 10: Publication title along with the number of papers.

Several guidelines are suggested by the researcher for conducting a systematic literature review. The guidelines are followed in the proposed system literature survey $[16,17]$. The following sections briefly show the research method and protocol followed for conducting the proposed study. Figure 1 shows the generic process of conducting the SLR.
2.1. Research Plan and Method. For conducting an efficient and successful search process, the following famous libraries were searched in order to get most relevant materials:

(i) $\mathrm{ACM}$

(ii) IEEE Xplore 


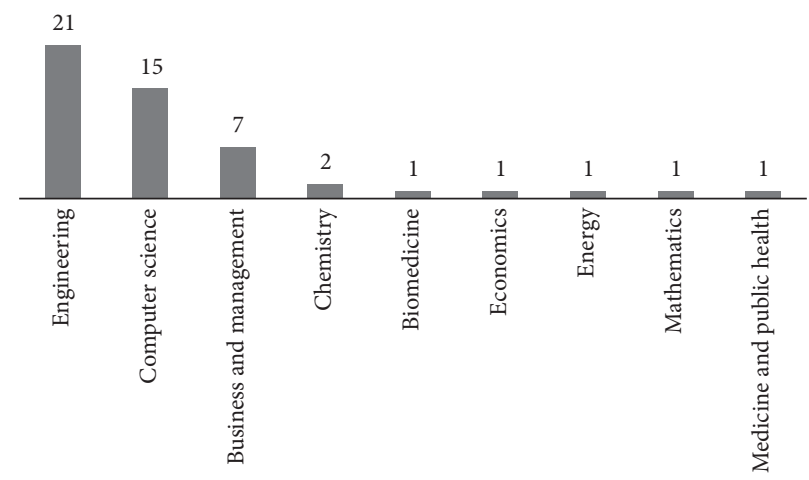

- Number of paper

Figure 11: Disciplines of publications with their number of papers.

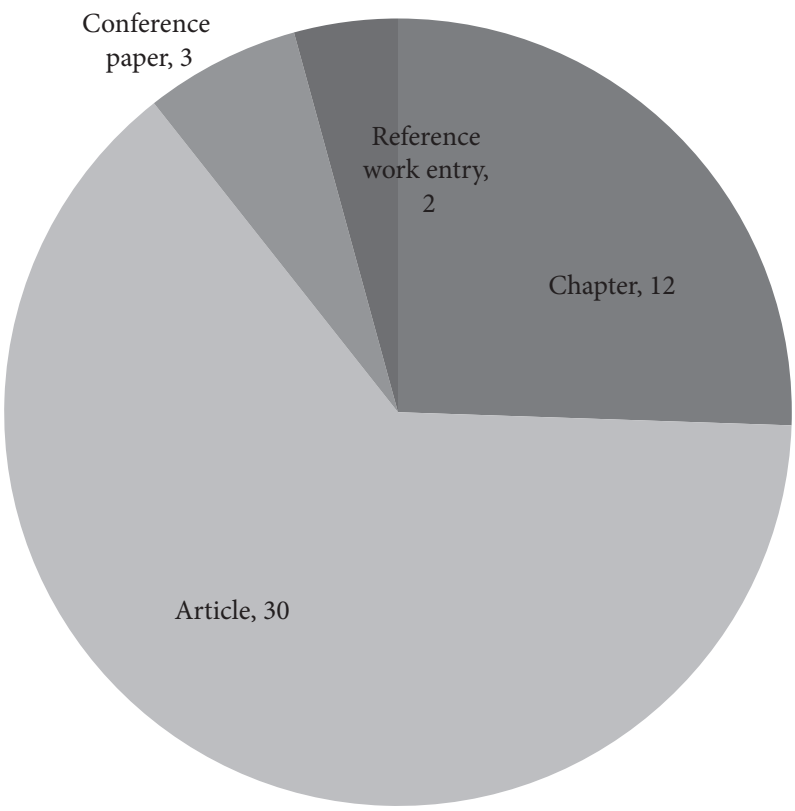

Figure 12: Publication type with their number of papers.
(iii) ScienceDirect
(iv) Springer
(v) Taylor and Francis
(vi) Wiley Online

2.2. Research Questions. The following are the research questions (RQs) of the proposed study:

(i) RQ1: what are the techniques and applications of multicriteria decision in big data?

(ii) RQ2: what are the applications of deep learning algorithms in big data?

(iii) RQ3: how to analyze the existing literature for the applications of multicriteria and deep learning algorithms in big data?
2.3. Search Process. The search process is very tricky due to the reason that a paper should not be missed. Six popular libraries that are ACM, IEEE, ScienceDirect, Springer, Taylor and Francis, and Wiley Online were considered for the search process. Initially, research questions were defined. The reason behind the selection of these libraries is that these libraries are dominant in the field and publishing quality research work which are mostly peer reviewed. After that, the following keywords were defined with different Boolean operators to search the query:

("Deep learning" OR "Machine learning") AND ("multi-criteria” OR “MCDM") AND ("big data” OR "Data")

Searching the libraries by the individual keywords is not an effective way to select appropriate materials. So, for this, the keywords were combined by logical 


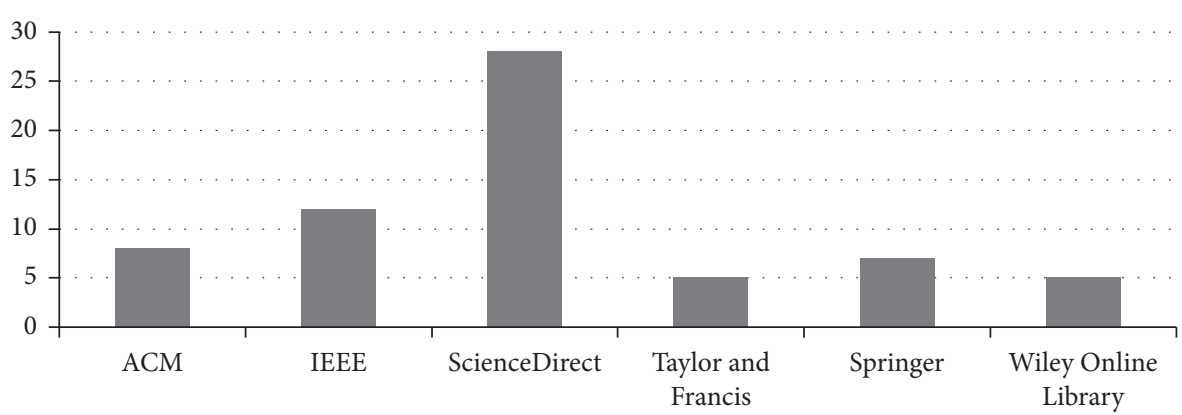

Figure 13: Number of the selected studies in the given libraries.

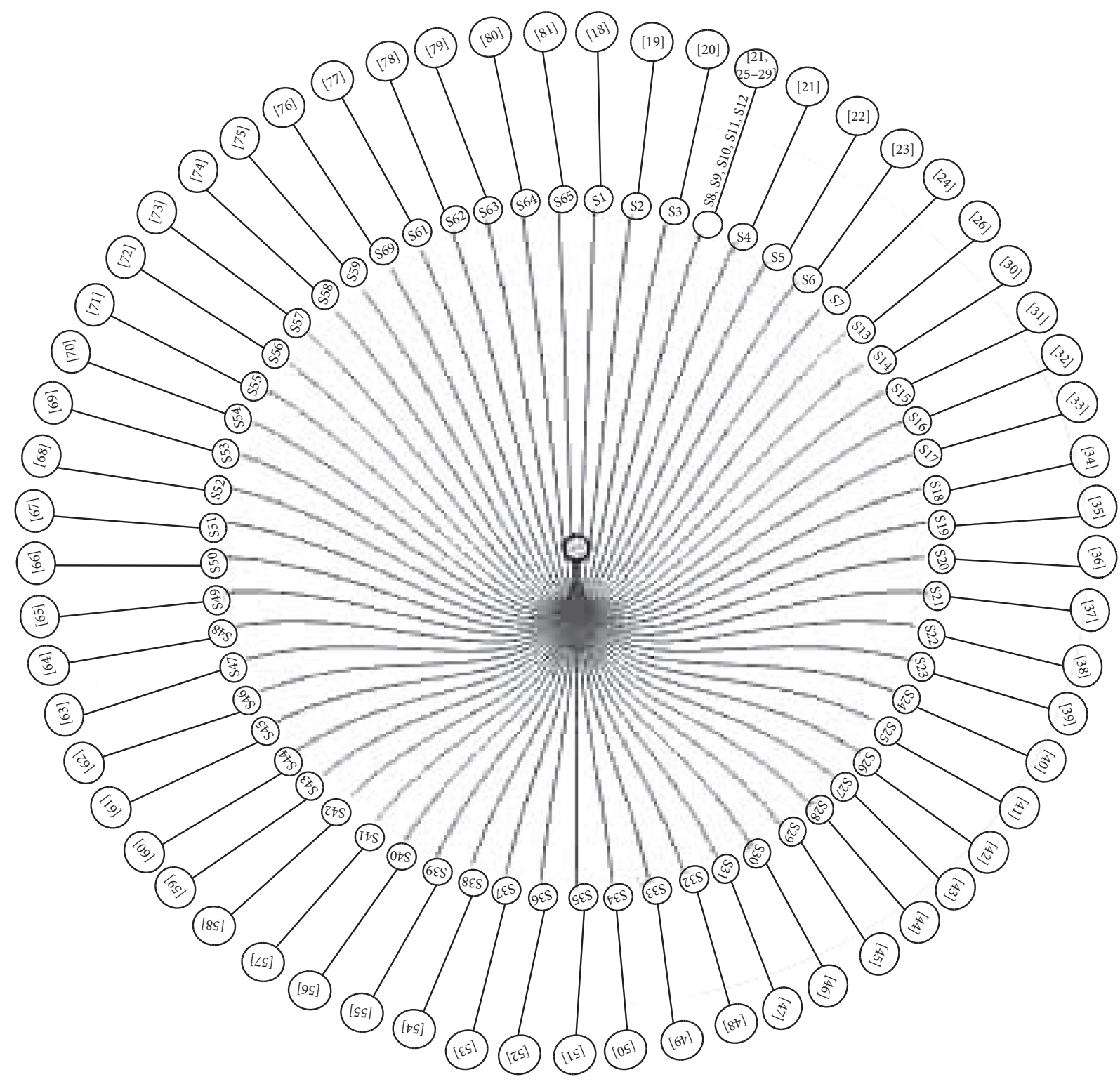

FIGURE 14: List of the selected papers.

operators such as "AND" and "OR" to formulate effective queries. The formulated query for search is then applied on each library to select papers that are published in the last 5 years (2016-2020). As only single keyword is not enough to identify relevant research studies, similar keywords are identified for each of the keyword term. 


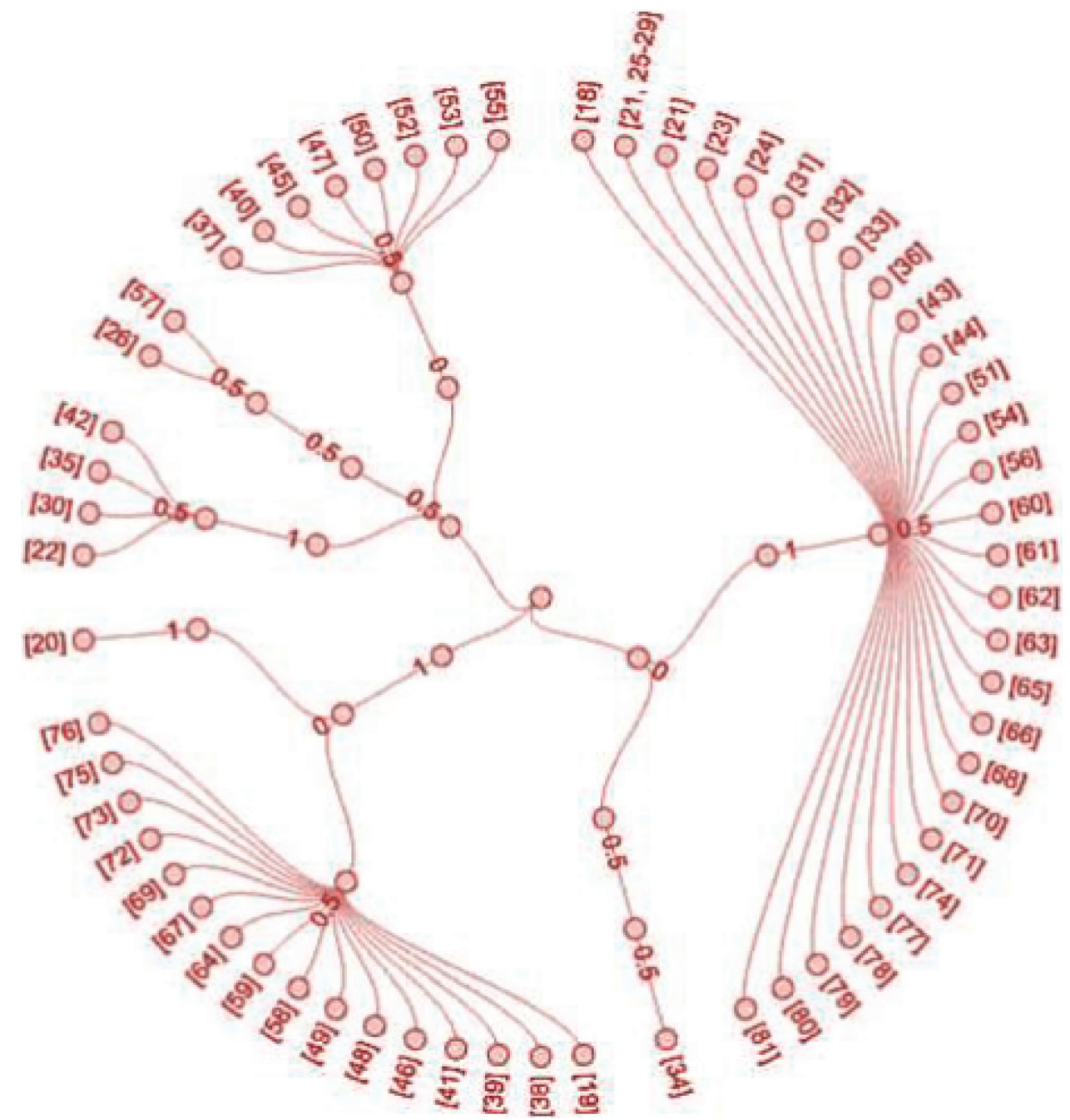

FIGURE 15: Quality evaluation of the selected papers.

Figure 2 shows the process of conducting the search and filtering process.

2.4. Study Selection. The designed query was searched in the specified libraries in order to obtain the relevant associated materials for the proposed study. Among these libraries, the filtering process was performed for the year range from 2016 to 2020. Using this procedure, query is applied and search results are obtained, which is shown in detail in Table 1.

From each of the libraries, the papers were filtered by title, abstract, and content. All the papers are then analysed based on its contents, and the most final set of relevant papers is selected. The final selected papers are analysed to answer the research questions and to achieve the objectives of the study. Figure 3 shows the search and filtering results in the given libraries.

Figure 4 shows the initial results of the journal/magazine names along with the total number of publications in the ACM library.

Figure 5 shows the proceeding names with the number of publications.
Figure 6 shows the content types along with the number of publications.

Figure 7 shows the publication topics along with the number of papers in the IEEE library.

Figure 8 shows the number of publications in the given year in the ScienceDirect library.

Figure 9 shows the article type along with the number of papers.

Figure 10 shows the publication title with the number of papers.

Figure 11 shows the publication disciplines in the Springer library.

Figure 12 shows the publication type with their number of papers.

Figure 13 shows the number of selected papers in all the given libraries including ACM, IEEE, ScienceDirect, Springer, Tailor and Francis, and Wiley Online Library.

The final list of the selected papers is given in Figure 14.

2.5. Quality Assessment. The quality of the selected papers was aimed to check for showing the relevancy of the 


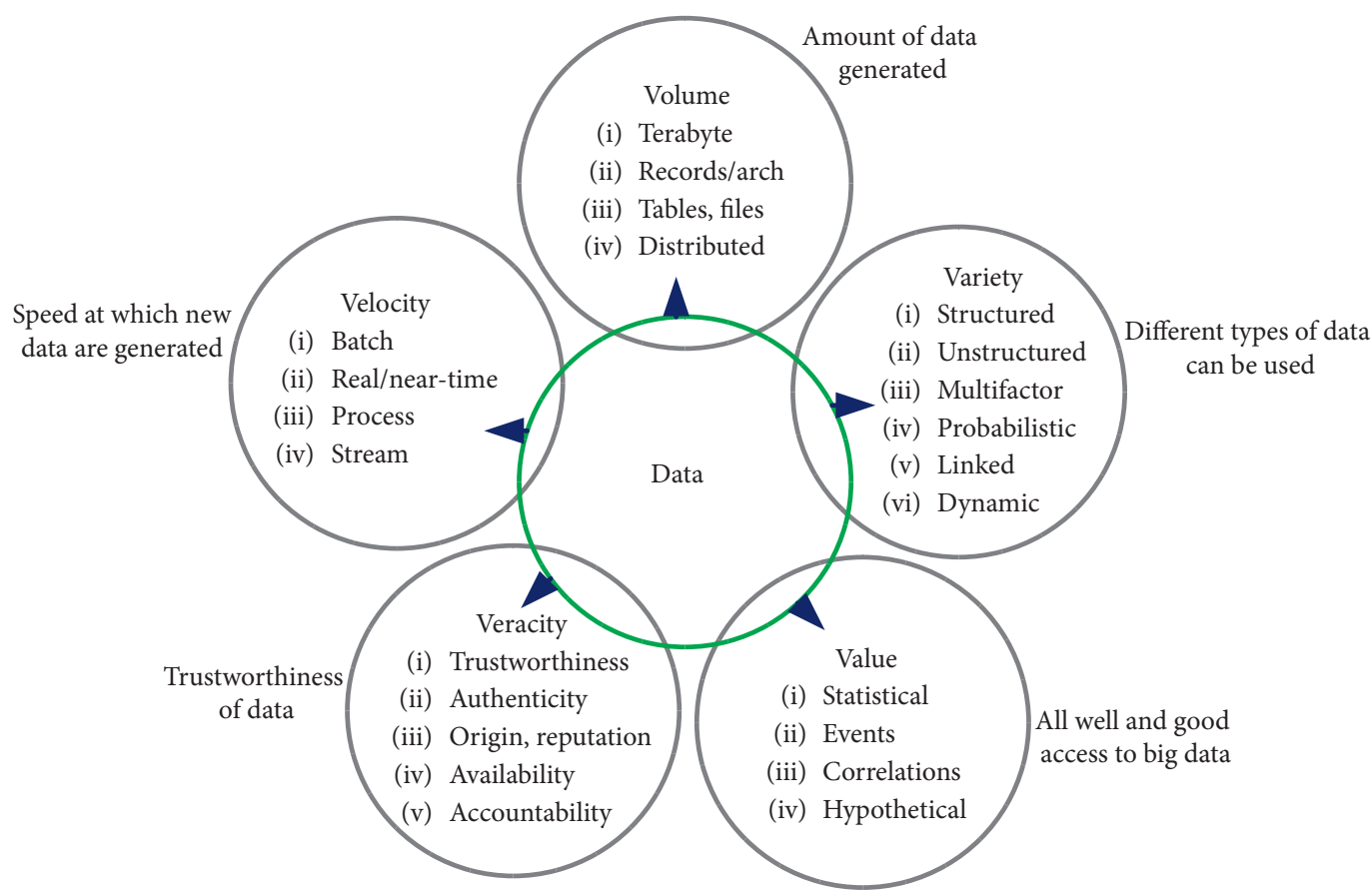

Figure 16: 5 Vs of data.

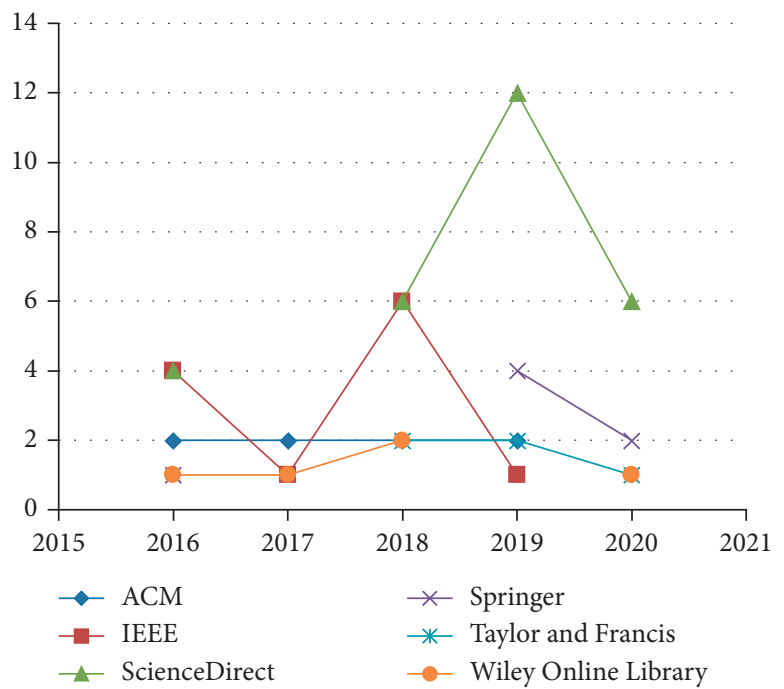

Figure 17: Number of publications in given years and libraries.

selected papers to the proposed research. Scores of $0,0.5$, and 1 were adopted to give a score to the research questions based on the specific research paper. The score 0 was given to the paper which do not satisfy the research question, 0.5 for the paper which partially satisfies the research question, and 1 for paper which fully satisfies the research questions. The quality evaluation of selected papers is depicted in Figure 15.

\section{Results and Discussion}

Big data contains a huge amount of information which needs to be extracted for a specific purpose of the user.
Such kind of data is very difficult to manage, organize, and structure. Various tools are used for extracting meaningful information and insights. The applications of machine learning algorithms play an important role in real life. The machine learning has been used mostly for classification purposes [18]. Figure 16 shows the $5 \mathrm{Vs}$ of big data.

Several types of analysis were done to show the impact, number of publications, and the increase in research activities in the popular libraries. In this analysis, maybe some relevant papers are missed due to the search query and some other reasons. Figure 17 shows the number of publications in the given libraries. 


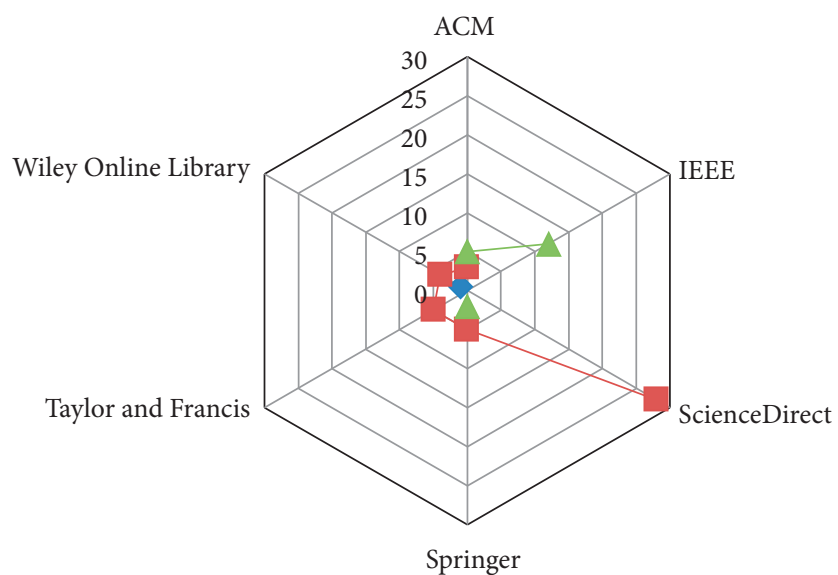

$$
\begin{aligned}
& \longleftarrow \text { Book } \quad \longleftarrow \text { Conference } \\
& \longleftarrow \text { Journal } \quad \star \text { Others }
\end{aligned}
$$

FIGURE 18: Type of publications along with the number of papers in the given libraries.

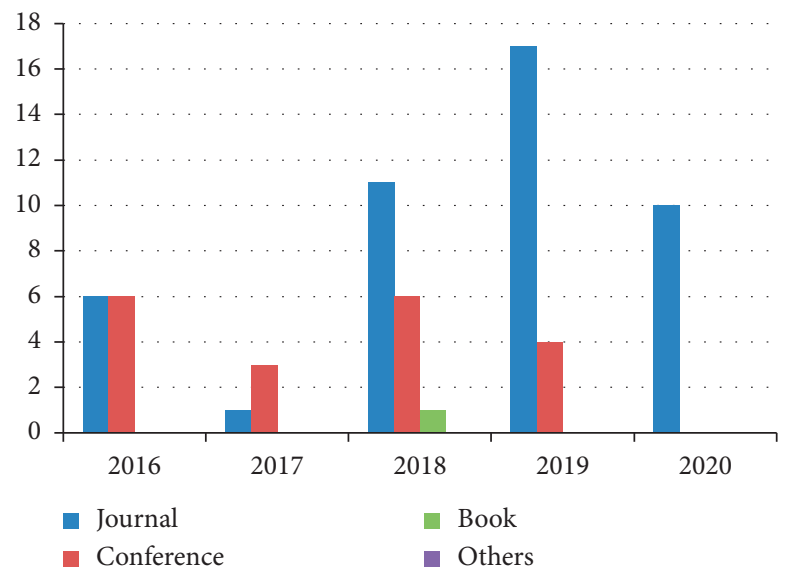

Figure 19: Year and article type.

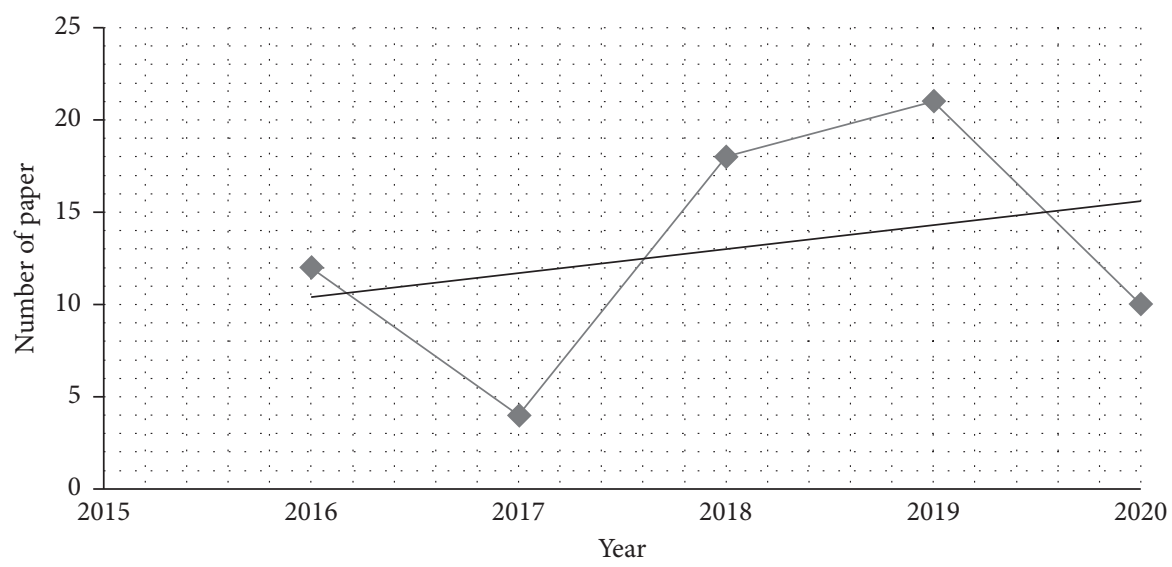

Figure 20: Number of papers in the given years.

Figure 18 shows the type of publications along with the number of papers in the given libraries.

Figure 19 shows the year and type of publication.
Figure 20 shows the number of papers in the given year. Table 2 shows the details of the answers to the research questions with the method used along with the description. 
TABLE 2: Details of the answers to the research question defined for the proposed research.

\begin{tabular}{|c|c|c|c|c|c|}
\hline Citation & Method & Description & RQ1 & RQ2 & RQ3 \\
\hline [19] & $\begin{array}{l}\text { Support vector machine for classifications of } \\
\text { biomedical signal on the platform of IoT }\end{array}$ & $\begin{array}{l}\text { The authors proposed an approach for observing the } \\
\text { signal using the digital signal processor and then } \\
\text { measured the heart rate, blood oxygen saturation, } \\
\text { and blood pressure. SVM is used for classification } \\
\text { purpose, and it showed the data into unhealthy, } \\
\text { healthy, and very unhealthy and described the } \\
\text { accuracy of prediction classification. }\end{array}$ & & $\sqrt{ }$ & $\sqrt{ }$ \\
\hline [20] & $\begin{array}{c}\text { Treatments of hypertension based on big data using } \\
\text { machine learning (ML) }\end{array}$ & $\begin{array}{l}\text { Application of ML algorithms for big data in } \\
\text { achieving insights into the management of } \\
\text { hypertension disease. The decision tree and neural } \\
\text { networks are used as ML techniques to identify the } \\
\text { factors to contribute in hypertension drug } \\
\text { treatment. }\end{array}$ & & $\sqrt{ }$ & $\sqrt{ }$ \\
\hline
\end{tabular}

Various technologies related to data mining for the disease of heart are discussed. These techniques can help in early prediction of heart disease. Some of these techniques are classification involving decision

Big data analytics and data mining for predicting the heart disease

tree, Naïve Bayes, genetic algorithm, neural network, $\mathrm{AI}$, and clustering algorithms such as support vector machine and KNN. The proposed review presents details of the available prediction models from the year 2004 to 2016 which uses data mining.

The basic and potentiality of ML algorithms are Applications of the ML algorithm in cardiovascular described. The issues and assessments of the needs of medicine ML algorithms in cardiovascular medicine are discussed.

Comparative study of different classifiers such KNN, Naïve Bayes, SVM, NN, Gaussian mixture model, and decision tree has been done in order to achieve good performance in critical prediction of cardiac arrest. This comparison was done behind the reason as a specific classifiers may or may not work very well in a particular case (dataset).

[23] Study on comparisons of different ML classifiers on data of medical

$$
\text { Techniques of unsupervised machine learning }
$$

$[22,26-30]$ Deep learning and machine learning

Bioinformatics is classified into voluminous, incremental database, and techniques of composite data analytics. These datasets such as DNA and RNA contain huge information which is termed as big data.

Techniques of ML are used for extracting information from these datasets.

The data of Facebook walls of 153 different organizations were analysed to extract information about the performances and engagement of the user based on unsupervised techniques of ML

The two-fold model of big data is presented for healthcare. Firstly, they presented the issues in the existing mobile healthcare system, while in the second phase mHealth 2.0, they proposed techniques of ML and deep neural networks for the processing of big data and information retrieving purpose that ensure the efficiency, time saving, data integrity, and manageable solution for making the healthcare green. The techniques have applications

in the intensive care unit for essential health monitoring of the patients. cloud primarily focuses on applying technique of ML for predicting health status of the patients based

$\sqrt{ } \quad \sqrt{ } \quad \sqrt{ }$


TABLE 2: Continued.

\begin{tabular}{|c|c|c|c|c|c|}
\hline Citation & Method & Description & RQ1 & RQ2 & RQ3 \\
\hline$[31]$ & $\begin{array}{c}\text { Healthcare big data security through machine } \\
\text { learning }\end{array}$ & $\begin{array}{l}\text { The study proposed an integrated technique based } \\
\text { on masking encryption, granular access control, } \\
\text { activity monitoring, dynamic data encryption, and } \\
\text { models of endpoint validation. The proposed system } \\
\text { results by providing an efficient diagnostic system } \\
\text { for disease in the healthcare-based big data system. }\end{array}$ & $\sqrt{ }$ & $\sqrt{ }$ & $\sqrt{ }$ \\
\hline$[32]$ & $\begin{array}{l}\text { Application of the deep learning network in left } \\
\text { ventricular volume prediction in cardiac MRI }\end{array}$ & $\begin{array}{l}\text { The authors developed left ventricular volume } \\
\text { prediction approach without segmentation by deep } \\
\text { learning technology and the data set form large-scale } \\
\text { cardiac MRI from the second annual data science } \\
\text { bowl in } 2016 \text {. }\end{array}$ & & $\sqrt{ }$ & $\sqrt{ }$ \\
\hline [33] & $\begin{array}{l}\text { Applications of machine learning and analytical } \\
\text { hierarchy process for risk assessment }\end{array}$ & $\begin{array}{l}\text { The authors presented multicriteria decision } \\
\text { methods and machine learning algorithms for } \\
\text { assessment of risk of oil and gas pipeline defects }\end{array}$ & & $\sqrt{ }$ & $\sqrt{ }$ \\
\hline$[34]$ & $\begin{array}{l}\text { A metaheuristic approach for developing } \\
\text { PROAFTN with the decision tree }\end{array}$ & $\begin{array}{l}\text { The authors presented an MCDA-based method } \\
\text { called PROAFTN as a fuzzy classification method. } \\
\text { The method used data preprocessing and genetic } \\
\text { algorithm for extracting parameters from the data. }\end{array}$ & & $\sqrt{ }$ & $\sqrt{ }$ \\
\hline$[35]$ & Fuzzy set theory for active learning & $\begin{array}{c}\text { The concept of fuzzy set theory is presented for } \\
\text { learning }\end{array}$ & & $\sqrt{ }$ & $\sqrt{ }$ \\
\hline$[36]$ & Deep learning networks for limited data & $\begin{array}{l}\text { Deep networks for limited data to calculate the } \\
\text { uncertainty are presented }\end{array}$ & $\sqrt{ }$ & $\sqrt{ }$ & $\sqrt{ }$ \\
\hline
\end{tabular}

The authors presented an approach to cover

[37] MCDS for evaluation of RES methodology developed and the tools for processing $\quad \sqrt{ }$ resource data

\begin{tabular}{|c|c|c|c|c|}
\hline [38] & $\begin{array}{l}\text { Leveraging ensemble pruning for imbalanced data } \\
\text { classification }\end{array}$ & $\begin{array}{c}\text { Integrated pruning algorithm is presented for } \\
\text { imbalanced data }\end{array}$ & $\sqrt{ }$ & $\sqrt{ }$ \\
\hline
\end{tabular}

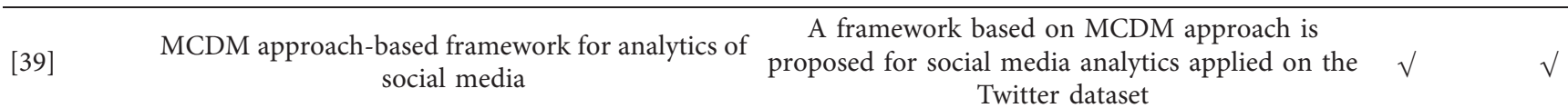
social media $\quad$ Twitter dataset
proposed for social media analytics

[40] Selecting dig data reference architecture through

Literature review and application of comparison of the software architecture analysis method and existing big data reference architecture are found $\sqrt{ } \quad \sqrt{ }$ and compared. The AHP was used, and the experiment was done through the real-world use case.

[41]

$$
\begin{aligned}
& \text { Video trajectory analysis using unsupervised } \\
& \text { clustering and multicriteria ranking }
\end{aligned}
$$

Analytics of big data is used for solving the damages caused with alarms. The method integrates technique of interdisciplinary and accomplishing analytics with evidential inference.

The unsupervised trajectory method of cluster ( $\mathrm{t}$ cluster) is proposed. The method creates object indexes by fusing high-level interpretable features, $\begin{array}{lll}\sqrt{ } & \sqrt{ }\end{array}$ then the clusters are fused through MCDM, and trajectories are ranked accordingly.

[43] Visual analytics and machine learning

The authors reported the existing literature by highlighting and integrating the advances in the machine learning and visual analytics

The author presented a novel model of classification

Applications of machine learning for early detection and treatment outcome prediction

for general purpose and for launching reliable predictive rules for the applications of biology and medical

Resource provisioning for applications of deep learning in smart healthcare
The authors presented a technique of proximity-

based provisioning of resources for avoiding delay in achieving inference results with the mobile cloud

system 
TABle 2: Continued.

\begin{tabular}{|c|c|c|c|c|c|}
\hline Citation & Method & Description & RQ1 & RQ2 & RQ3 \\
\hline [46] & Outlier reduction in web mining framework & $\begin{array}{l}\text { The study presented reducing outlier framework in } \\
\text { the analysis of regression with support of ordered } \\
\text { weighted operators as MCDM }\end{array}$ & $\sqrt{ }$ & & $\sqrt{ }$ \\
\hline [47] & $\begin{array}{c}\text { Flood susceptibility mapping of arid areas based on } \\
\text { GIS-based MCDM, southeastern Tunisia }\end{array}$ & $\begin{array}{l}\text { With the help of MCDM approach (AHP), an } \\
\text { attempt is made to prepare flood hazard } \\
\text { susceptibility map of the Gabes regions }\end{array}$ & $\sqrt{ }$ & & $\sqrt{ }$ \\
\hline [48] & Healthcare management and analytics of big data & $\begin{array}{l}\text { The existing literature is examined for the purpose of } \\
\text { reviewing the existing research and to derive new } \\
\text { agenda. }\end{array}$ & $\sqrt{ }$ & & $\sqrt{ }$ \\
\hline [49] & $\begin{array}{l}\text { The multicriteria quadratic programming model for } \\
\text { imbalanced data }\end{array}$ & $\begin{array}{l}\text { The paper presented a model of multiple criteria } \\
\text { quadratic programming by launching the cost of } \\
\text { misclassification to the multiple criteria quadratic } \\
\text { programming model }\end{array}$ & $\sqrt{ }$ & & $\sqrt{ }$ \\
\hline$[50]$ & $\begin{array}{l}\text { Clustering MCDM approach for analysis of big data } \\
\text { for evaluation of marketing strategies }\end{array}$ & $\begin{array}{l}\text { The strategy of digital bank has been recommended } \\
\text { applying big data for the banking industry of Iran. } \\
\text { The strategy would help the banks of Iran to } \\
\text { distinguish and analyze the needs of the customers } \\
\text { to offer services proportionate to their manner. }\end{array}$ & $\sqrt{ }$ & & $\sqrt{ }$ \\
\hline$[51]$ & Subgroup discovery in MOOCs & $\begin{array}{l}\text { The paper aims to describe and categorize diverse } \\
\text { types of learners in massive open online course by } \\
\text { the help of the subgroup discovery method based on } \\
\text { MapReduce }\end{array}$ & $\sqrt{ }$ & & $\sqrt{ }$ \\
\hline [52] & $\begin{array}{l}\text { Applications of machine learning algorithms in } \\
\text { treatment of oncology big data }\end{array}$ & $\begin{array}{l}\text { The study presented a decision-making systems } \\
\text { which is a part of user-centered healthcare based on } \\
\text { predicting cancer distribution }\end{array}$ & & $\sqrt{ }$ & $\sqrt{ }$ \\
\hline [53] & Wireless networks and analytics of big data & $\begin{array}{l}\text { A survey of the literature is presented for the } \\
\text { analytics of big data approaches in wireless networks }\end{array}$ & $\sqrt{ }$ & & $\sqrt{ }$ \\
\hline$[54]$ & $\begin{array}{c}\text { Open-source big data cognitive computing } \\
\text { platform }\end{array}$ & $\begin{array}{l}\text { The research has developed a platform for meeting } \\
\text { the need of user requirement analytics for the data } \\
\text { that are structured and unstructured }\end{array}$ & $\sqrt{ }$ & & $\sqrt{ }$ \\
\hline$[55]$ & $\begin{array}{l}\text { Floating car data and machine learning for traffic } \\
\text { prediction }\end{array}$ & $\begin{array}{l}\text { The presented approach detects the traffics in the } \\
\text { road networks of urban area through supervised } \\
\text { learning approach }\end{array}$ & & $\sqrt{ }$ & $\sqrt{ }$ \\
\hline [56] & $\begin{array}{l}\text { Using clustering techniques for selection of ideal } \\
\text { cloud services }\end{array}$ & $\begin{array}{c}\text { By using the approach, the user can enter the values } \\
\text { of his/her best service and the technique of } \\
\text { clustering; the nearest best service is selected and } \\
\text { returned to the user. }\end{array}$ & $\sqrt{ }$ & & $\sqrt{ }$ \\
\hline$[57]$ & $\begin{array}{l}\text { Integrating deep learning and argumentative } \\
\text { reasoning to analyze textual content of social media }\end{array}$ & $\begin{array}{l}\text { With the help of deep learning for relation-based } \\
\text { augment mining to derive augmentative relations of } \\
\text { support and attack }\end{array}$ & & $\sqrt{ }$ & $\sqrt{ }$ \\
\hline [58] & EXEHDA-RR & $\begin{array}{c}\text { The paper presented machine learning in } \\
\text { preclassification of the middleware resources of } \\
\text { EXEHDA to reduce cost of computation by MCDA } \\
\text { algorithms }\end{array}$ & $\sqrt{ }$ & $\sqrt{ }$ & $\sqrt{ }$ \\
\hline [59] & Social AHP & $\begin{array}{l}\text { The paper presented an approach for the services of } \\
\text { citizen-to-citizen interaction through AHP by using } \\
\text { the identified attributes and model of decision to } \\
\text { considering the social attributes }\end{array}$ & $\sqrt{ }$ & & $\sqrt{ }$ \\
\hline$[60]$ & $\begin{array}{l}\text { Approaches of MCDM for big data analytics } \\
\text { capabilities and firm performance }\end{array}$ & $\begin{array}{l}\text { With the help of MCDM methodology, the abilities } \\
\text { of big data analytics and the impact of these abilities } \\
\text { on performance of firm are explored }\end{array}$ & $\sqrt{ }$ & & $\sqrt{ }$ \\
\hline [61] & $\begin{array}{l}\text { Profitability performance in project tendering with } \\
\text { big data and deep learning for benchmarking }\end{array}$ & $\begin{array}{l}\text { The study developed a benchmark system for the } \\
\text { evaluation of tender using big data }\end{array}$ & & $\sqrt{ }$ & $\sqrt{ }$ \\
\hline
\end{tabular}


TABle 2: Continued.

\begin{tabular}{|c|c|c|c|c|c|}
\hline Citation & Method & Description & RQ1 & RQ2 & RQ3 \\
\hline$[62]$ & Big data and machine learning for game-predicting & $\begin{array}{l}\text { The research has developed ranking for teams and } \\
\text { players and designed a system for the answers of } \\
\text { managerial questions regarding the game of hockey. } \\
\text { With the help of } 18 \text { performance measure, the player } \\
\text { rating is done. The game of hockey is predicted using } \\
\text { big data and machine leaning. }\end{array}$ & & $\sqrt{ }$ & $\sqrt{ }$ \\
\hline [63] & $\begin{array}{l}\text { Image classification through multicriteria active } \\
\text { deep learning }\end{array}$ & $\begin{array}{l}\text { The study proposed multicriteria active deep } \\
\text { learning for learning strategy for deep neural } \\
\text { networks in the classification of image }\end{array}$ & & $\sqrt{ }$ & $\sqrt{ }$ \\
\hline [64] & $\begin{array}{c}\text { Classification of multiattribute inventory through } \\
\text { an integrated decision analytic framework of } \\
\text { machine learning with multicriteria decision- } \\
\text { making }\end{array}$ & $\begin{array}{l}\text { Multicriteria inventory classification approach was } \\
\text { presented through the integration of machine } \\
\text { learning with multicriteria decision-making }\end{array}$ & & $\sqrt{ }$ & $\sqrt{ }$ \\
\hline [65] & Decisions for marketing, supplying, and purchasing & $\begin{array}{l}\text { With the help of online review, a decision support } \\
\text { system is presented for measuring the stratification } \\
\text { of the customer }\end{array}$ & $\sqrt{ }$ & & $\sqrt{ }$ \\
\hline [66] & $\begin{array}{l}\text { Deep learning with GIS data for prediction of } \\
\text { automobile maintenance }\end{array}$ & $\begin{array}{l}\text { The research presented an approach of GIS data into } \\
\text { modelling of TBF, and it researched the impact on } \\
\text { automobile TBF with the help of deep learning }\end{array}$ & & $\sqrt{ }$ & $\sqrt{ }$ \\
\hline [67] & $\begin{array}{l}\text { Deep learning and data warehouse for depth } \\
\text { prediction of urban flood }\end{array}$ & $\begin{array}{l}\text { Deep learning and data warehouse were considered } \\
\text { for assessing the flood risk in urban areas }\end{array}$ & & $\sqrt{ }$ & $\sqrt{ }$ \\
\hline [68] & $\begin{array}{l}\text { Selecting cloud service through a hybrid } \\
\text { multicriteria decision }\end{array}$ & $\begin{array}{l}\text { MCDM approach was developed for the selection of } \\
\text { cloud services }\end{array}$ & $\sqrt{ }$ & & $\sqrt{ }$ \\
\hline [69] & $\begin{array}{c}\text { Machine learning-based traffic offloading in fog } \\
\text { networks }\end{array}$ & $\begin{array}{l}\text { The study presented an offloading solution and } \\
\text { shows different profiles for different proposes such } \\
\text { as to get maximum data rate, save battery, and so on }\end{array}$ & & $\sqrt{ }$ & $\sqrt{ }$ \\
\hline [70] & $\begin{array}{l}\text { Framework of IT for identifying high-quality } \\
\text { physicians using big data analytics }\end{array}$ & $\begin{array}{l}\text { With the help of signalling theory, high-quality } \\
\text { doctors are identifying based on the four-level } \\
\text { model }\end{array}$ & $\sqrt{ }$ & & $\sqrt{ }$ \\
\hline [71] & $\begin{array}{c}\text { Analysis of microarray leukemia data using an } \\
\text { efficient MapReduce-based KNN }\end{array}$ & $\begin{array}{l}\text { The study presented an approach by using } \\
\text { framework of Hadoop for classification of } \\
\text { microarray data. The KNN classifier was used for the } \\
\text { classification purpose of data. }\end{array}$ & & $\sqrt{ }$ & $\sqrt{ }$ \\
\hline$[72]$ & $\begin{array}{c}\text { Combining CNN streams of RGB-D and skeletal } \\
\text { data for recognition of human activity }\end{array}$ & $\begin{array}{l}\text { Convolution neural network-based approach is } \\
\text { proposed for the recognition of human activity }\end{array}$ & & $\sqrt{ }$ & $\sqrt{ }$ \\
\hline [73] & $\begin{array}{c}\text { Applying machine learning to the AHP } \\
\text { multicriteria decision-making method to asset } \\
\text { prioritization in the context of industrial } \\
\text { maintenance } 4.0\end{array}$ & $\begin{array}{l}\text { With the help of machine learning algorithms and } \\
\text { relevance analysis of attribute to process the event } \\
\text { log failure of components of industrial machine }\end{array}$ & $\sqrt{ }$ & & $\sqrt{ }$ \\
\hline [74] & Amended fused TOPSIS-VIKOR for classification & $\begin{array}{c}\text { The study presented a novel classification ATOVIC } \\
\text { based on fused VIKOR and TOPSIS }\end{array}$ & $\sqrt{ }$ & & $\sqrt{ }$ \\
\hline$[75]$ & $\begin{array}{l}\text { Machine learning models, epistemic set-valued } \\
\text { data, and generalized loss functions }\end{array}$ & $\begin{array}{l}\text { The research aim is to study the problem where the } \\
\text { goal is to identify optimal model to specific criteria } \\
\text { in supervised and regression classification problems }\end{array}$ & & $\sqrt{ }$ & $\sqrt{ }$ \\
\hline$[76]$ & $\begin{array}{l}\text { Framework for modelling of drug electrochemical } \\
\text { removal from wastewater based on data mining } \\
\text { algorithms, scatter interpolation method, and } \\
\text { multicriteria decision analysis }\end{array}$ & $\begin{array}{l}\text { The study presented a framework for modelling of } \\
\text { removal of drug from wastewater. With the help of } \\
\text { data mining algorithms, ciprofloxacin } \\
\text { electrochemical removal modelling is done and } \\
\text { MCDA is developed for ranking the algorithm of } \\
\text { data mining. }\end{array}$ & $\sqrt{ }$ & & $\sqrt{ }$ \\
\hline [77] & $\begin{array}{l}\text { Feature selection based on multicriteria on cost- } \\
\text { sensitive data with missing values }\end{array}$ & $\begin{array}{c}\text { An evaluation system based on multicriteria is } \\
\text { proposed for evaluating features from diverse } \\
\text { viewpoints }\end{array}$ & $\sqrt{ }$ & & $\sqrt{ }$ \\
\hline
\end{tabular}


TABLE 2: Continued.

\begin{tabular}{|c|c|c|c|c|c|}
\hline Citation & Method & Description & RQ1 & RQ2 & RQ3 \\
\hline [78] & $\begin{array}{c}\text { Frameworks of ML and data mining for prediction } \\
\text { of drug response in cancer }\end{array}$ & $\begin{array}{l}\text { The study gives an overview of the supervised and } \\
\text { unsupervised algorithms used in the prediction of } \\
\text { drug response, the strategies applied for designing } \\
\text { these algorithms into functional models, data } \\
\text { resources for feeding to frameworks, and challenges } \\
\text { for maximizing the performance of the models }\end{array}$ & & $\sqrt{ }$ & $\sqrt{ }$ \\
\hline [79] & $\begin{array}{l}\text { Data fusion and machine learning for industrial } \\
\text { prognosis }\end{array}$ & $\begin{array}{l}\text { The study overviewed the literature in data fusion } \\
\text { and analysis for industrial prognosis }\end{array}$ & & $\sqrt{ }$ & $\sqrt{ }$ \\
\hline [80] & $\begin{array}{c}\text { A supervised machine learning approach to data- } \\
\text { driven simulation }\end{array}$ & $\begin{array}{l}\text { With the help of data analytics, the risk profiles of } \\
\text { supplier performance based on uncertainty are } \\
\text { analysed }\end{array}$ & & $\sqrt{ }$ & $\sqrt{ }$ \\
\hline [81] & $\begin{array}{l}\text { Machine learning model-based favourite data to } \\
\text { analyze asymmetric competition }\end{array}$ & $\begin{array}{l}\text { The study presented an approach for analysis of } \\
\text { asymmetric competition based on favourite data } \\
\text { with the help of machine learning algorithms }\end{array}$ & & $\sqrt{ }$ & $\sqrt{ }$ \\
\hline [82] & $\begin{array}{l}\text { Machine learning powered software for accurate } \\
\text { prediction of biogas production }\end{array}$ & $\begin{array}{l}\text { The study presented machine learning approaches } \\
\text { for biogas production data from projects of China }\end{array}$ & & $\sqrt{ }$ & $\sqrt{ }$ \\
\hline
\end{tabular}

\section{Conclusion}

With the current advancements in technology, the data are ever increasing with the increase in population, communications, IoT, actuators, sensors, and so on. This increase goes into different shapes of data whose decision becomes a challenging issue due to its growth of volume. Deep learning algorithms and multicriteria-based decision-making have effective applications in big data. Due to its effectiveness and potentiality, it is exploited in several domains such as computer science and information technology, agriculture, and business sector. The aim of the proposed study is to present a systematic literature in order to show the applications of deep learning algorithms and multicriteria decision approaches for the problems of big data. The research finds novel means to make the decision support system for the problems of big data using multiple criteria in integration with machine learning and artificial intelligence approaches. The presented study will provide better insights into the research community in the area domain and will help them in the designing of more robust, efficient, and effective multicriteria-based decision support system models, framework, technique, and integrated solutions of machine learning algorithms.

\section{Data Availability}

No data are available.

\section{Conflicts of Interest}

No conflicts of interest exist regarding this paper.

\section{References}

[1] IDC, "Analyze the future," 2014, http://www.idc.com/.

[2] M. Hilbert and P. López, "The world's technological capacity to store, communicate, and compute information," Science, vol. 332, no. 6025, pp. 60-65, 2011.

[3] S. D. Sagiroglu, "Big data: a review," in Proceedings of the International Conference on Collaboration Technologies and Systems (CTS'13), pp. 42-47, San Diego, CA, USA, 2013.
[4] S. Nazir, S. Shahzad, I. Zada, and H. Khan, "Evaluation of software birthmarks using fuzzy analytic hierarchy process," in Proceedings of the Fourth International Multi-Topic Conference, pp. 171-175, Jamshoro, Pakistan, 2015.

[5] S. Nazir, S. Shahzad, Z. Hussain, M. Iqbal, and A. Keerio, "Evaluating student grades using analytic network process," Sindh University Research Journal (Science Series), vol. 47, pp. 1-5, 2015.

[6] S. Nazir, S. Anwar, S. A. Khan et al., "Software component selection based on quality criteria using the analytic network process," Abstract and Applied Analysis, vol. 2014, Article ID 535970, 12 pages, 2014.

[7] S. Nazir, S. Shahzad, M. Nazir, and H. U. Rehman, "Evaluating security of software components using analytic network process," in Proceedings of the 11th International Conference on Frontiers of Information Technology (FIT), IEEE, Islamabad, Pakistan, pp. 183-188, 2013.

[8] S. Safdar, S. Zafar, N. Zafar, and N. F. Khan, "Machine learning based decision support systems (DSS) for heart disease diagnosis: a review," Artificial Intelligence Review, vol. 50, no. 4, pp. 597-623, 2018.

[9] I. Aouadni and A. Rebai, "Decision support system based on genetic algorithm and multi-criteria satisfaction analysis (MUSA) method for measuring job satisfaction," Annals of Operations Research, vol. 256, no. 1, pp. 3-20, 2017.

[10] M. Jemmali, M. Alharbi, and L. K. B. Melhim, "Intelligent decision-making algorithm for supplier evaluation based on multi-criteria preferences," in Proceedings of the 2018 1st International Conference on Computer Applications \& Information Security (ICCAIS), pp. 1-5, Riyadh, Saudi Arabia, 2018.

[11] C. Fleig, D. Augenstein, and A. Maedche, Designing a Process Mining-Enabled Decision Support System for Business Process Standardization in ERP Implementation Projects, pp. 228-244, Springer, Cham, Switzerland, 2018.

[12] A. Schwenk-Ferrero and A. Andrianov, "Nuclear waste management decision-making support with MCDA," Science and Technology of Nuclear Installations, vol. 2017, Article ID 9029406, 20 pages, 2017.

[13] I. Petkovics, J. Simon, A. Petkovics, and Z. Čović, "Selection of unmanned aerial vehicle for precision agriculture with multicriteria decision making algorithm," in Proceedings of the 2017 
IEEE 15th International Symposium on Intelligent Systems and Informatics (SISY), pp. 000151-000156, Subotica, Serbia, 2017.

[14] L. S. R. Supriadi and L. Sui Pheng, "Knowledge based decision support system (KBDSS)," in Business Continuity Management in Construction, pp. 155-174, Springer, Singapore, 2018.

[15] A. Alaeddini and K. G. Murty, "DSS (decision support system) for allocating appointment times to calling patients at a medical facility," in Case Studies in Operations Research: Applications of Optimal Decision Making, K. G. Murty, Ed., pp. 83-109, Springer New York, New York, NY, 2015.

[16] S. Keele, "Guidelines for performing systematic literature reviews in software engineering," Ver. 2.3 EBSE Technical Report, EBSE, Durham, England, 2007.

[17] B. Kitchenham and S. Charters, "Guidelines for performing systematic literature reviews in software engineering," EBSE Technical Report EBSE-2007-01, Evidence-Based Software Engineering, Keele, England, 2007.

[18] S. Khan, N. Islam, Z. Jan, I. Ud Din, and J. J. P. C. Rodrigues, "A novel deep learning based framework for the detection and classification of breast cancer using transfer learning," Pattern Recognition Letters, vol. 125, pp. 1-6, 2019.

[19] S.-W. Liou, D. Kurniadi, B.-R. Zheng, W.-Q. Xie, C.-J. Tien, and G.-J. Jong, "Classification of biomedical signal on IoT platform using support vector machine," in Proceedings of the 2018 IEEE International Conference on Applied System Invention (ICASI), pp. 50-53, 2018.

[20] G. Koren, G. Nordon, K. Radinsky, and V. Shalev, "Machine learning of big data in gaining insight into successful treatment of hypertension," Pharmacology Research \& Perspectives, vol. 6, no. 3, Article ID e00396, 2018.

[21] N. K. S. Banu and S. Swamy, "Prediction of heart disease at early stage using data mining and big data analytics: a survey," in Proceedings of the 2016 International Conference on Electrical, Electronics, Communication, Computer and Optimization Techniques (ICEECCOT), pp. 256-261, Mysuru, India, 2016.

[22] K. Shameer, K. W. Johnson, B. S. Glicksberg, J. T. Dudley, and P. P. Sengupta, "Machine learning in cardiovascular medicine: are we there yet?" Heart, vol. 104, no. 14, pp. 1156-1164, 2018.

[23] N. Karankar, P. Shukla, and N. Agrawal, "Comparative study of various machine learning classifiers on medical data," in Proceedings of the 2017 7th International Conference on Communication Systems and Network Technologies (CSNT), pp. 267-271, Chandigarh, India, 2017.

[24] H. Kashyap, H. A. Ahmed, N. Hoque, S. Roy, and D. K. Bhattacharyya, "Big data analytics in bioinformatics: architectures, techniques, tools and issues," Network Modeling Analysis in Health Informatics and Bioinformatics, vol. 5, p. 28, 2016.

[25] N. Straton, K. Hansen, R. R. Mukkamala et al., "Big social data analytics for public health: facebook engagement and performance," in Proceedings of the 2016 IEEE 18th International Conference on e-Health Networking, Applications and Services (Healthcom), pp. 1-6, Munich, Germany, 2016.

[26] R. S. H. Istepanian and T. Al-Anzi, "m-Health 2.0: new perspectives on mobile health, machine learning and big data analytics," Methods, vol. 151, pp. 34-40, 2018.

[27] L. R. Nair, S. D. Shetty, and S. D. Shetty, "Applying spark based machine learning model on streaming big data for health status prediction," Computers \& Electrical Engineering, vol. 65, pp. 393-399, 2018.

[28] H. B. Patel and S. Gandhi, "A review on big data analytics in healthcare using machine learning approaches," in Proceedings of the 2018 2nd International Conference on Trends in
Electronics and Informatics (ICOEI), pp. 84-90, Tirunelveli, India, 2018.

[29] A. Muniasamy, S. Tabassam, M. A. Hussain, H. Sultana, V. Muniasamy, and R. Bhatnagar, "Deep learning for predictive analytics in healthcare," in Proceedings of the International Conference on Advanced Machine Learning Technologies and Applications, pp. 32-42, Cairo, Egypt, 2019.

[30] R. Venkatesh, C. Balasubramanian, and M. Kaliappan, "Development of big data predictive analytics model for disease prediction using machine learning technique," Journal of Medical Systems, vol. 43, p. 272, 2019.

[31] P. Kaur, M. Sharma, and M. Mittal, "Big data and machine learning based secure healthcare framework," Procedia Computer Science, vol. 132, pp. 1049-1059, 2018.

[32] G. Luo, G. Sun, K. Wang, S. Dong, and H. Zhang, "A novel left ventricular volumes prediction method based on deep learning network in cardiac MRI," in Proceedings of the 2016 Computing in Cardiology Conference (CinC), pp. 89-92, Vancouver, British Columbia, 2016.

[33] A. Ouadah, "Pipeline defects risk assessment using machine learning and analytical hierarchy process," in Proceedings of the 2018 International Conference on Applied Smart Systems (ICASS), pp. 1-6, Medea, Algeria, 2018.

[34] F. Al-Obeidat, B. Shah, A. M. Khattak, and A. Abbas, "A metaheuristic approach for developing PROAFTN with decision tree," in Proceedings of the 2016 3rd MEC International Conference on Big Data and Smart City (ICBDSC), pp. 1-7, Muscat, Oman, 2016.

[35] F. Hu, L. Zhou, J. Dai, and K. Liu, "A method of active learning based on fuzzy set theory," in Proceedings of the 2019 IEEE 4th International Conference on Cloud Computing and Big Data Analysis (ICCCBDA), pp. 695-700, Chengdu, China, 2019.

[36] A. Hoblitzell, M. Babbar-Sebens, and S. Mukhopadhyay, "Uncertainty-based deep learning networks for limited data wetland user models," in Proceedings of the 2018 IEEE International Conference on Artificial Intelligence and Virtual Reality (AIVR), pp. 19-26, Taichung, Taiwan, 2018.

[37] R. Mukhamediev, R. Mustakayev, K. Yakunin, S. Kiseleva, and V. Gopejenko, "Multi-criteria decision support system for RES evaluation," in Proceedings of the 2018 IEEE 12th International Conference on Application of Information and Communication Technologies (AICT), pp. 1-6, Kazakhstan, Almaty, 2018.

[38] B. Krawczyk and M. Wozniak, "Leveraging ensemble pruning for imbalanced data classification," in Proceedings of the 2018 IEEE International Conference on Systems, Man, and Cybernetics (SMC), pp. 439-444, Miyazaki, Japan, 2018.

[39] A. Muruganantham and G. M. Gandhi, "Framework for social media analytics based on multi-criteria decision making (MCDM) model," Multimedia Tools and Applications, vol. 79, pp. 3913-3927, 2020.

[40] M. Volk, S. Bosse, D. Bischoff, and K. Turowski, "Decisionsupport for selecting big data reference architectures," in Proceedings of the International Conference on Business Information Systems, pp. 3-17, Seville, Spain, 2019.

[41] Y.-C. Ko, Y.-Y. Ting, and H. Fujita, "A visual analytics with evidential inference for big data: case study of chemical vapor deposition in solar company," Granular Computing, vol. 4, no. 3, pp. 531-544, 2019.

[42] A. A. Sekh, D. P. Dogra, S. Kar, and P. P. Roy, "Video trajectory analysis using unsupervised clustering and multicriteria ranking," Soft Computing, 2020. 
[43] A. Endert, W. Ribarsky, C. Turkay et al., "The state of the art in integrating machine learning into visual analytics," Computer Graphics Forum, vol. 36, no. 8, pp. 458-486, 2017.

[44] E. K. Lee, "Machine learning for early detection and treatment outcome prediction," in Decision Analytics and Optimization in Disease Prevention and Treatment, pp. 367-400, Wiley, Hoboken, NJ, USA, 2018.

[45] D. Sivan, M. Sellappa, and J. Dinesh Peter, "Proximity-based cloud resource provisioning for deep learning applications in smart healthcare," Expert Systems, Article ID e12524, 2020.

[46] A. Gupta and S. Kohli, "OWA operator-based hybrid framework for outlier reduction in web mining," International Journal of Intelligent Systems, vol. 31, no. 10, pp. 947-962, 2016.

[47] D. Souissi, L. Zouhri, S. Hammami, M. H. Msaddek, A. Zghibi, and M. Dlala, "GIS-based MCDM-AHP modeling for flood susceptibility mapping of arid areas, southeastern Tunisia," Geocarto International, vol. 35, no. 9, pp. 991-1017, 2020.

[48] S. S. Kamble, A. Gunasekaran, M. Goswami, and J. Manda, “A systematic perspective on the applications of big data analytics in healthcare management," International Journal of Healthcare Management, vol. 12, no. 3, pp. 226-240, 2018.

[49] X. Chao and Y. Peng, "A cost-sensitive multi-criteria quadratic programming model for imbalanced data," Journal of the Operational Research Society, vol. 69, no. 4, pp. 500-516, 2018.

[50] H. A. Mahdiraji, E. Kazimieras Zavadskas, A. Kazeminia, and A. Abbasi Kamardi, "Marketing strategies evaluation based on big data analysis: a CLUSTERING-MCDM approach," Economic Research-Ekonomska Istraživanja, vol. 32, no. 1, pp. 2882-2898, 2019.

[51] J. M. Luna, H. M. Fardoun, F. Padillo, C. Romero, and S. Ventura, "Subgroup discovery in MOOCs: a big data application for describing different types of learners," Interactive Learning Environments, pp. 1-19, 2019.

[52] M. Zouiten, "Machine learning algorithms for oncology big data treatment," in Proceedings of the 2nd International Conference on Computing and Wireless Communication Systems, Association for Computing Machinery, Larache, Morocco, 2017.

[53] D. Hong-Ning, W. Raymond Chi-Wing, W. Hao, Z. Zibin, and V. V. Athanasios, "Big data analytics for large-scale wireless networks: challenges and opportunities," ACM Computing Surveys, vol. 52, no. 5, pp. 1-36, 2019.

[54] K. Michael and A. V. Mladen, "Developing an open source "big data" cognitive computing platform: big data (ubiquity symposium)," Ubiquity, vol. 2018, pp. 1-15, 2018.

[55] M. Mzibri, A. Maach, and A. Elhadri, "A novel traffic prediction system based on floating car data and machine learning," in Proceedings of the 2nd International Conference on Networking, Information Systems \& Security, Association for Computing Machinery, Rabat, Morocco, 2019.

[56] R. Hajar, I. Abdellah, and A. Manar, "The research and selection of ideal cloud services using clustering techniques: track: big data, data mining, cloud computing and remote sensing," in Proceedings of the International Conference on Big Data and Advanced Wireless Technologies, Association for Computing Machinery, Blagoevgrad, Bulgaria, 2016.

[57] C. Oana and T. Francesca, "Combining deep learning and argumentative reasoning for the analysis of social media textual content using small data sets," Computational Linguistics, vol. 44, no. 4, pp. 833-858, 2018.

[58] D. Renato, F. Huberto Kaiser, P. Ana Marilza, and Y. Adenauer, "EXEHDA-RR: machine learning and MCDA with semantic web in IoT resources classification," in Proceedings of the 23rd Brazillian Symposium on Multimedia and the Web, Association for Computing Machinery, Gramado, Brazil, 2017.

[59] A. Chouikh and A. Ojo, "Enabling new public service paradigms on social media platforms: a "social AHP" model for citizen-to-citizen services," in Proceedings of the 17th International Digital Government Research Conference on Digital Government Research, pp. 534-535, Shanghai China, June 2016.

[60] M. Yasmin, E. Tatoglu, H. S. Kilic, S. Zaim, and D. Delen, "Big data analytics capabilities and firm performance: an integrated MCDM approach," Journal of Business Research, vol. 114, pp. 1-15, 2020.

[61] M. Bilal and L. O. Oyedele, "Big Data with deep learning for benchmarking profitability performance in project tendering," Expert Systems with Applications, vol. 147, Article ID 113194, 2020.

[62] W. Gu, K. Foster, J. Shang, and L. Wei, "A game-predicting expert system using big data and machine learning," Expert Systems with Applications, vol. 130, pp. 293-305, 2019.

[63] J. Yuan, X. Hou, Y. Xiao, D. Cao, W. Guan, and L. Nie, "Multicriteria active deep learning for image classification," Knowledge-Based Systems, vol. 172, pp. 86-94, 2019.

[64] H. Kartal, A. Oztekin, A. Gunasekaran, and F. Cebi, "An integrated decision analytic framework of machine learning with multi-criteria decision making for multi-attribute inventory classification," Computers \& Industrial Engineering, vol. 101, pp. 599-613, 2016.

[65] S. Çalı and Ş. Y. Balaman, "Improved decisions for marketing, supply and purchasing: mining big data through an integration of sentiment analysis and intuitionistic fuzzy multi criteria assessment," Computers \& Industrial Engineering, vol. 129, pp. 315-332, 2019.

[66] C. Chen, Y. Liu, X. Sun, C. D. Cairano-Gilfedder, and S. Titmus, "Automobile maintenance prediction using deep learning with GIS data," Procedia CIRP, vol. 81, pp. 447-452, 2019.

[67] Z. Wu, Y. Zhou, H. Wang, and Z. Jiang, "Depth prediction of urban flood under different rainfall return periods based on deep learning and data warehouse," Science of The Total Environment, vol. 716, Article ID 137077, 2020.

[68] A. Al-Faifi, B. Song, M. M. Hassan, A. Alamri, and A. Gumaei, "A hybrid multi criteria decision method for cloud service selection from Smart data," Future Generation Computer Systems, vol. 93, pp. 43-57, 2019.

[69] G.-E. Zaharia, T.-A.-I. Şoşea, R.-I. Ciobanu, and C. Dobre, "Machine learning-Based traffic offloading in fog networks," Simulation Modelling Practice and Theory, vol. 101, Article ID 102045, 2020.

[70] Y. Ye, Y. Zhao, J. Shang, and L. Zhang, "A hybrid IT framework for identifying high-quality physicians using big data analytics," International Journal of Information Management, vol. 47, pp. 65-75, 2019.

[71] M. Kumar, N. K. Rath, and S. K. Rath, "Analysis of microarray leukemia data using an efficient MapReduce-based K-nearestneighbor classifier," Journal of Biomedical Informatics, vol. 60, pp. 395-409, 2016.

[72] P. Khaire, P. Kumar, and J. Imran, "Combining CNN streams of RGB-D and skeletal data for human activity recognition," Pattern Recognition Letters, vol. 115, pp. 107-116, 2018.

[73] E. Lima, E. Gorski, E. F. R. Loures, E. A. P. Santos, and F. Deschamps, "Applying machine learning to AHP multicriteria decision making method to assets prioritization in the 
context of industrial maintenance 4.0," IFAC-PapersOnLine, vol. 52, no. 13, pp. 2152-2157, 2019.

[74] L. Baccou, "Amended fused TOPSIS-VIKOR for classification (ATOVIC) applied to some UCI data sets," Expert Systems with Applications, vol. 99, pp. 115-125, 2018.

[75] I. Couso and L. Sánchez, "Machine learning models, epistemic set-valued data and generalized loss functions: an encompassing approach," Information Sciences, vol. 358-359, pp. 129-150, 2016.

[76] S. Farzin, F. N. Chianeh, M. V. Anaraki, and F. Mahmoudian, "Introducing a framework for modeling of drug electrochemical removal from wastewater based on data mining algorithms, scatter interpolation method, and multi criteria decision analysis (DID)," Journal of Cleaner Production, vol. 266, Article ID 122075, 2020.

[77] W. Shu and H. Shen, "Multi-criteria feature selection on costsensitive data with missing values," Pattern Recognition, vol. 51, pp. 268-280, 2016.

[78] K. Vougas, T. Sakellaropoulos, A. Kotsinas, G.-R. P. Foukas, and V. G. Gorgoulis, "Machine learning and data mining frameworks for predicting drug response in cancer: an overview and a novel in silico screening process based on association rule mining," Pharmacology \& Therapeutics, vol. 203, Article ID 107395, 2019.

[79] A. Diez-Olivan, J. Del Ser, D. Galar, and B. Sierra, "Data fusion and machine learning for industrial prognosis: trends and perspectives towards industry 4.0," Information Fusion, vol. 50, pp. 92-111, 2019.

[80] I. M. Cavalcante, E. M. Frazzon, F. A. Forcellini, and D. Ivanov, "A supervised machine learning approach to datadriven simulation of resilient supplier selection in digital manufacturing," International Journal of Information Management, vol. 49, pp. 86-97, 2019.

[81] Y. Liu, Y. Qian, Y. Jiang, and J. Shang, "Using favorite data to analyze asymmetric competition: machine learning models," European Journal of Operational Research, vol. 287, no. 2, pp. $600-615,2020$.

[82] D. D. Clercq, D. Jalota, R. Shang, K. Ni, and K. Yuan, "Machine learning powered software for accurate prediction of biogas production: a case study on industrial-scale Chinese production data," Journal of Cleaner Production, vol. 218, pp. 390-399, 2019. 